\title{
Viajantes naturalistas do século XIX na região da Província de Goiás: levantamento de topônimos indígenas
}

\section{Naturalist travelers of the 19th century in the region of the Province of Goias:} cataloging of the indigenous toponyms

\author{
Carla Bastiani* \\ Universidade Federal do Tocantins \\ Palmas, Tocantins, Brasil \\ Karylleila dos Santos Andrade** \\ Universidade Federal do Tocantins \\ Palmas, Tocantins, Brasil
}

\begin{abstract}
Resumo: Apresentando-se como um recorte do Atlas Toponímico do Tocantins - ATT, este estudo visa descrever a toponímia indígena dos viajantes naturalistas no século XIX na região da Província de Goiás, hoje Estado do Tocantins. Ressalta-se que esses relatos são elementos fundamentais na construção da identidade nacional. No caso dessa província, essas narrações permitem reconstituir, além da história e geografia regional, seu perfil etnolinguístico. Os procedimentos metodológicos utilizados foram: leitura de textos sobre a historiografia da Província de Goiás e dos relatos dos viajantes naturalistas europeus do século XIX; levantamento dos topônimos indígenas (etnotopônimos) descritos nesses relatos; e análise do corpus a partir dos subsídios da toponímia de Dick (1990).
\end{abstract}

Palavras-chave: Etnotoponímia. Província de Goiás. Século XIX. Viajantes naturalistas europeus.

\begin{abstract}
Presenting as a cut of the Toponymic Atlas of Tocantins - ATT, this study aims to describe the indigenous toponymia of naturalist travelers in the 19th century in the region of Goiás Province, today State of Tocantins. It is worth emphasizing that these reports are fundamental elements in the construction of the national identity. In the case of this province, these narratives allow to reconstitute, in addition to regional history and geography, its ethnolinguistic profile. The methodological procedures used were: reading texts on the historiography of the Province of Goiás and reports of nineteenth-century European naturalists; cataloging of the indigenous toponyms described in these reports (ethnotoponyms); and analysis of the corpus based on Dick's toponymy subsidies (1990).
\end{abstract}

Keywords: Ethnotoponymia. Province of Goiás. 19th century. European naturalist travelers.

\footnotetext{
*Doutoranda do Programa de Pós-Graduação em Letras - PPGL - Universidade Federal do Tocantins, Palmas, Tocantins, Brasil. E-mail: carlabastiani@gmail.com.

** Professora do Programa de Pós-Graduação em Letras - PPGL - Universidade Federal do Tocantins, Palmas, Tocantins, Brasil. E-mail: karylleila@gmail.com.
} 


\section{INTRODUÇÃO}

Enquanto manifestação concreta da linguagem, é por meio da língua que os indivíduos constroem as suas relações nos diversos ambientes em que interagem no interior de uma sociedade. É a língua o instrumento que viabiliza essa interação bem como a expressão de ideias, sentimentos e intenções. Nessa perspectiva, a língua pode ser entendida como um fato social e, a partir dessa compreensão, analisada a partir de sua relação com a estrutura de uma sociedade (BASTIANI, 2016, p. 189).

Sapir (1969, p, 20) já dizia que a língua é "um guia para a realidade social", evidenciando a necessidade de pensar a língua em sua relação imanente com a sociedade e com a cultura, isto é, considerando-a como parte da realidade sociocultural de uma comunidade e vendo no léxico a projeção do universo de significados e experiências inerentes ao contexto de mundo de uma comunidade de falantes.

A visão de mundo que cada sociedade tem de seu contexto circundante é única, e essa visão particularizada faz com que essa comunidade use a língua de maneira singular para expressar a realidade observada, sendo o léxico, portanto, produto social portador de uma carga cultural significativa. Ao perceber a realidade ao seu próprio modo, a comunidade também nomeia sob um ponto de vista característico os elementos que fazem parte do seu espaço - sejam eles lugares, pessoas, animais ou objetos -, de modo que os nomes se constituem como elementos nos quais subjazem a imagem do mundo e o modus vivendi dessa comunidade (BASTIANI, 2016, p. 189).

Ao fazer uso de sua habilidade linguística para nomear tudo aquilo que perfaz o seu mundo, o homem imprime nos nomes que batizam os elementos que o rodeiam traços de sua cultura, da sua história e da sua ideologia, marcas essas que podem ser visualizadas nos nomes de lugares, ao se levar em consideração as influências socioculturais que incidem sob a escolha desses nomes.

A Toponímia é a disciplina científica voltada ao estudo dos nomes de lugares, os topônimos, e busca resgatar as motivações desses nomes. Esse trabalho de resgate pode possibilitar que se desvende algo da expressão psicossocial e cultural de um grupo de falantes em um determinado recorte temporal devido ao caráter conservador que o topônimo carrega em si.

Nesse sentido, com o objetivo de conhecer e popularizar as especificidades naturais, socioeconômicas e histórico-culturais do território brasileiro, o século XIX é marcado na história do Brasil como uma época de inúmeras visitas que ao país fizeram eminentes personalidades, entre elas notáveis viajantes naturalistas. Auguste François César Provençal de Saint-Hilaire, Johann Emmanuel Pohl, George Gardner e Francis Castelnau foram alguns deles que, no curso de suas expedições, visitaram a Província de Goiás.

Os relatos desses viajantes são alguns dos elementos fundamentais na construção da identidade nacional. No caso da Província de Goiás, essas narrações permitem reconstituir, além da história e geografia regional, seu perfil etnolinguístico, ainda que o discurso utilizado nessas fontes seja acentuadamente etnocêntrico, pelo fato de ser condicionado pelos valores da cultura europeia, e revele a falta de empatia na percepção da alteridade que os viajantes naturalistas adotaram diante de suas observações. 
A despeito dessas impressões tendenciosas, cabe ressaltar que, enquanto cientistas, esses viajantes sentiram a necessidade de conhecer os nomes dos lugares, da fauna, da flora, dos elementos geomorfológicos, da cultura espiritual, dos grupos indígenas, entre outros, mas principalmente de compreender a etimologia desses nomes. Como subsídio para tal empreendimento, contaram com documentos oficiais e registros da tradição oral. Levando em consideração o fato de que os topônimos de origem indígena (etnotopônimos) eram constantes nos relatos desses viajantes, em virtude da gama de povos indígenas que povoavam a Província de Goiás no século XIX, o objetivo deste estudo é fazer um levantamento e uma descrição dos etnotopônimos catalogados por eles na região da Província de Goiás, hoje Estado do Tocantins.

Deve-se esclarecer que esta pesquisa apresenta-se como um recorte do Atlas Toponímico do Tocantins - ATT, seguindo a mesma lógica de trabalho desse projeto. Nesse sentido, para a realização deste estudo, a metodologia adotada foi: leitura de textos sobre a historiografia da região da Província de Goiás; leitura dos relatos dos viajantes naturalistas europeus do século XIX referentes à Província de Goiás (Auguste François César Provençal de Saint-Hilaire, Johann Emmanuel Pohl, Francis Castelnau e George Gardner); levantamento dos topônimos indígenas (etnotopônimos) descritos nesses relatos; e análise do corpus a partir dos subsídios da toponímia (DICK, 1990).

\section{HISTÓRIA DA PROVÍNCIA DE GOIÁS: OLHARES DOS VIAJANTES NATURALISTAS ESTRANGEIROS}

No período compreendido entre o século XVI até fins do século XVIII, a produção científica e intelectual brasileira era escassa. O governo português, assim que tomou posse do território brasileiro, visando resguardar informações sobre as potencialidades econômicas e os recursos exploráveis, vetou a entrada de estrangeiros no país, o que garantiu a Portugal o monopólio de exploração e comércio da Colônia, conforme assinala Andrade (2010).

A importância de divulgar conhecimentos de natureza científica sobre o país somente foi percebida pelas autoridades com a instalação da Corte Joanina. Em 1808, D. João VI assinou o Decreto de Abertura dos Portos Brasileiros às Nações Amigas, invalidando o antigo embargo que outrora fora imposto à entrada de estrangeiros no país, dando ruptura ao antigo sistema colonial.

Uma das principais metas adotadas pelo governo de D. João VI foi inserir o Brasil no círculo das monarquias europeias pelas vias diplomáticas e, assim, retirar o país da fase de obscurantismo em que estava imerso. Uma vez que o país não dispunha de uma estrutura educacional erudita, foi necessário fomentar a vinda de cientistas estrangeiros para que pudessem conhecer e popularizar as especificidades naturais, socioeconômicas e histórico-culturais do território brasileiro.

O século XIX é marcado na história do Brasil como uma época de inúmeras visitas que ao país fizeram ilustres personalidades e estudiosos - zoólogos, geógrafos, geólogos, mineralogistas e numerosos eminentes naturalistas -, que se sentiram atraídos pelas possibilidades de pesquisas e descobertas que o novo e imenso território do Brasil lhes 
oferecia. Entre os naturalistas, destacam-se Johann Emmanuel Pohl, Auguste François César Provençal de Saint-Hilaire, George Gardner e Francis Castelnau.

O discurso dos viajantes estrangeiros na descrição do Brasil, particularmente da Província de Goiás, foi influenciado por doutrinas científicas e filosóficas em voga na passagem do século XIX para o século XX. Para eles, o determinismo, o evolucionismo e o positivismo servem como fundamento para explicar a realidade social do país em razão de sua constituição étnica. Essas teorias foram importadas, traduzidas, incorporadas e adaptadas pela elite intelectual brasileira da época, que delas igualmente se utilizava como respaldo para explicar a questão da mestiçagem, uma vez que buscava construir uma identidade nacional, preocupando-se com os problemas e as condições reais do país.

As diversas modalidades textuais identificadas na produção literária dos viajantes, crônicas, memórias, testemunhos, entrevistas e relatos da tradição oral, são marcadas por ideias etnocêntricas, especialmente no caso da Província de Goiás. O olhar desses viajantes é marcado pelo estranhamento e pela falta de parâmetros na percepção da alteridade. Motivados pela cosmovisão europeia e ignorando as especificidades históricas, sociais e culturais da população goiana, os viajantes estrangeiros, na construção de suas narrativas, mostram-se, em diversos momentos, acentuadamente etnocêntricos. A realidade não é analisada objetivamente, mas, sim, de forma impressionista. São as normas e os valores europeus tidos como preferíveis e como modelos de avaliação dos costumes dos povos visitados.

O principal interesse das expedições estrangeiras que aportavam no território brasileiro recaia sobre biomas como a Floresta Amazônica, o Pantanal e a Mata Atlântica. Demonstravam ainda interesse em conhecer as técnicas utilizadas na extração de ouro na Província de Minas Gerais, embora a produção aurífera estivesse decadente e deixado de ser a base da economia do país no início do século XIX. A Província de Goiás, tanto pela sua localização geográfica quanto pela situação socioeconômica que atravessava, não se prestava de modo propício aos olhares eurocêntricos dos viajantes. Sobre isso, Andrade (2010) salienta que

a província passava por uma crise decorrente da quase extinta produção aurífera, antes motivo de explosão demográfica. Agora, com a queda da atividade mineratória, Goiás vivia uma economia primária de subsistência, que, aos olhos dos viajantes, era a própria decadência. Insistiam em estabelecer "verdades", a partir de suas visões deturpadas da realidade goiana. O fato de não compreenderem a realidade local impulsionou-os a emitir julgamentos e opiniões com base em seus olhares etnocêntricos. (ANDRADE, 2010, p. 41)

Retomando a fala da autora acima, cumpre assinalar que a exploração aurífera na Província de Goiás se inicia em 1726, tendo sua fase de apogeu em 1750. Após a sensível diminuição da extração mineratória, assim como ocorreu nas Províncias de Minas Gerais e Mato Grosso, essa região vivenciou um período de decadência. De acordo com Chaul (2002), os viajantes estrangeiros

chegavam à terra imaginando um Goiás em esplendor devido à mineração, que atrelara a região à cadeia da produção capitalista, elo presente na corrente do progresso, mas se deparavam com uma província onde a crise imperava em seus múltiplos aspectos. Os olhares 
dos viajantes europeus conseguiam ver apenas um deserto de homens, sem comércio e sem perspectivas, com estradas fantasmas e ócio correndo nas veias do povo mestiço, longe por demais dos exemplos e do labor anglo-saxões. (CHAUL, 2002, p. 51)

Percebe-se que os viajantes europeus, ao se depararem com uma província que jazia na crise em seus diversos aspectos (econômicos, sociais e culturais), não compreendiam as razões que levaram a Província àquela situação. A realidade de Goiás era a do abandono e da miséria. $\mathrm{O}$ acesso à região era precário, o caráter das atividades da população era assistemático, as perspectivas eram ínfimas ou inexistentes. Diante desse panorama, interpretaram a realidade observada a partir do eurocentrismo, a partir de seus próprios valores e visões de mundo, razão que lhes confere, muitas vezes, um discurso etnocêntrico.

A seguir, far-se-á uma análise das impressões dos viajantes naturalistas Saint-Hilaire, Pohl, Gardner e Castelnau, no que diz respeito às suas excursões pela Província de Goiás no século XIX, região essa que atualmente compreende parte do território do Estado do Tocantins, bem como um levantamento e uma descrição de topônimos de origem indígena identificados por eles. Importa esclarecer que somente alguns topônimos foram aqui descritos devido às particularidades desta publicação no se refere ao número de páginas.

\subsection{AUGUST FRANÇOIS CÉSAR PROVENÇAL DE SAINT-HILAIRE}

Saint-Hilaire foi um ilustre naturalista francês que, sob a influência do Conde de Luxemburgo, embaixador da França, veio ao Brasil em 1816, permanecendo neste país até o ano de 1822. Em seu roteiro de viagem, explorou as regiões do Rio de Janeiro, Minas Gerais, Espírito Santo, Goiás, São Paulo, Santa Catarina e Rio Grande do Sul.

O principal interesse desse viajante em suas excursões recaía em estudos botânicos, chegando a reunir um herbário de 30.000 espécimes, que abrangia 7.000 espécies, muitas das quais até então avaliadas como desconhecidas. Além disso, coletou material de origem zoológica e forneceu impressões sobre aspectos econômicos, políticos e culturais da sociedade em geral.

Na província de Goiás, permaneceu de maio a setembro de 1819. Assim como nas demais províncias visitadas, Saint-Hilaire fornece informações sobre a situação socioeconômica e política dessa população, sem deixar de aludir aos aspectos culturais da mesma. Ademais, faz apontamentos sobre a fauna, a flora, o clima e os meios de comunicação dessa região.

O clima da América é mais favorável ao homem de cor que aos europeus, a raça caucasoide tende a se enfraquecer na América do Sul e a raça africana a se fortalecer. Enfraquecidos, irritados pelo calor das regiões tropicais, os homens da raça caucásica tornam-se apáticos e perdem a alegria. (SAINT-HILAIRE, 1975, p. 51)

Considerando a fala do viajante, é possível perceber que a interpretação do ambiente é feita com base em si mesmo, nos seus próprios signos e significados, valores 


\section{Revista \\ A Cor das Letras}

e visões de mundo. Segundo Andrade (2010, p. 52), "Saint-Hilaire apresenta-se, em seus relatos, desfavorável à miscigenação das raças, defendendo um conteúdo ideológico determinista e racial, impregnado de uma visão etnocêntrica”.

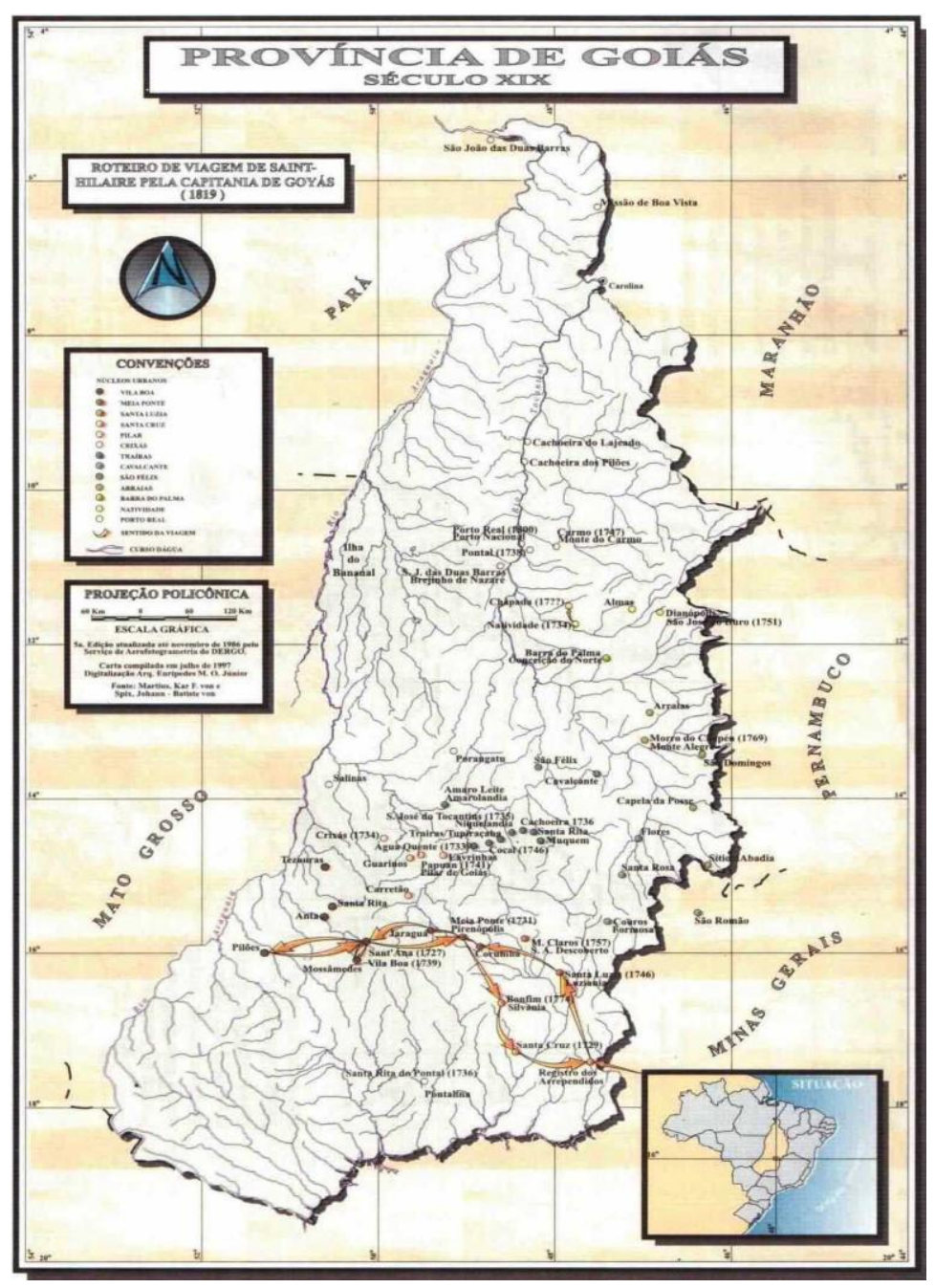

Figura 1: Mapa da viagem de Saint-Hilaire Fonte: Doles e Nunes (1992, p. 47)

Quadro 1 - Topônimos identificados por Saint-Hilaire (1975)

\begin{tabular}{|l|l|}
\hline $\begin{array}{l}\text { Topônimo } \\
\text { indígena }\end{array}$ & \multicolumn{1}{c|}{ Etimologia de Sampaio (1987) } \\
\hline $\begin{array}{l}\text { Córrego do } \\
\text { Jaraguá }\end{array}$ & $\begin{array}{l}\text {-Corr. Yara-guá, a baixa do senhor, o vale do dono. Pode ser corrupção } \\
\text { de yara-guã, que significa o dedo de Deus, a ponta do senhor. São } \\
\text { Paulo. Goiás, Alagoas. }\end{array}$ \\
\hline
\end{tabular}




\begin{tabular}{|l|l|}
\hline $\begin{array}{l}\text { Rio } \\
\text { Tocantins }\end{array}$ & $\begin{array}{l}\text { - Corr. Tucan-tim, nariz de tucano. Nome de um gentio que deu apelido } \\
\text { ao rio. Pará. Goiás. Alt. Tocantim. }\end{array}$ \\
\hline Rio Urubu & - Corr. Urú-bũ, a galinha preta, a ave negra (Cathartes). Alt. Urumú. \\
\hline $\begin{array}{l}\text { Serra do } \\
\text { Corumbá }\end{array}$ & - Corr. Curu-mbá, o banco de cascalho. Mato Grosso. \\
\hline
\end{tabular}

Fonte: Elaboração própria

\subsection{JOHAN EMANUEL POHL}

Renomado médico, mineralogista e botânico austríaco, Johan Emanuel Pohl esteve no Brasil entre os anos de 1817 e 1821 . Esse naturalista fez parte da Missão Austríaca que veio ao Brasil por ocasião do casamento da Arquiduquesa Leopoldina com Dom Pedro I. Durante sua permanência no Brasil, visitou inúmeras regiões, coletando vasto material mineralógico e cerca de 4.000 espécies de plantas, levando consigo esse material científico para Viena, em 1821.

Pohl visitou, primeiramente, Angra dos Reis. Depois do Rio de Janeiro, foi a São João Del Rei, passando por Barbacena. Em seguida, foi a Paracatu do Príncipe, de onde seguiu para a capital da Capitania de Goiás. Nessa Província, visitou os Arraiais de Santa Luzia, Meia Ponte, Anicuns e Pilões, além das Aldeias de São José de Mossâmedes e de Maria.

Segundo Andrade (2010), a sensação dos viajantes diante da situação da Província de Goiás era a de decadência. Acostumados ao pleno processo de industrialização que estava ocorrendo nas sociedades europeias, ao se depararem com uma província que jazia em crise, em decorrência da queda da atividade mineratória, só conseguiam enxergar atraso.

Pohl (1976) reitera o discurso etnocêntrico dos outros viajantes ao observar a cultura e o caráter social do povo goiano, afiançando que

estes homes, apesar de necessitados, trabalham somente a seu bel-prazer. Enquanto têm uns vinténs no bolso, não mexem com as mãos. Conheci alguns desses elementos que tiravam a roupa suja e ficavam debaixo de uma árvore até que a negra a levasse e secasse ao sol; então tornavam a vesti-la e entregavam-se à ociosidade, sem se animarem a trabalhar para melhorarem a sua condição. Mas o pior é que pelo emprego de seu tempo desperdiçado perdem somas incrivelmente exorbitantes. Uma das peculiaridades deste país é que os habitantes parecem prontos a travar relações de amizades com o estrangeiro; o que é apenas um pretexto para atrair a pessoa e depois fazer-se pagar cinicamente pelo menor favor. As trapaças são frequentes e não se pode dar um vintém adiantado sem ser logrado. (POHL, 1976, p. 142)

Tendo em vista o relato acima, verifica-se que esse viajante, por estar imbuído de uma concepção capitalista, interpreta o cotidiano da população da Província de Goiás de forma impressionista, caracterizando-o pela ociosidade, uma vez que os costumes que observa são refratários ao que determinava essa concepção. 


\section{Revista \\ ${ }_{A}$ Cor das Letras}

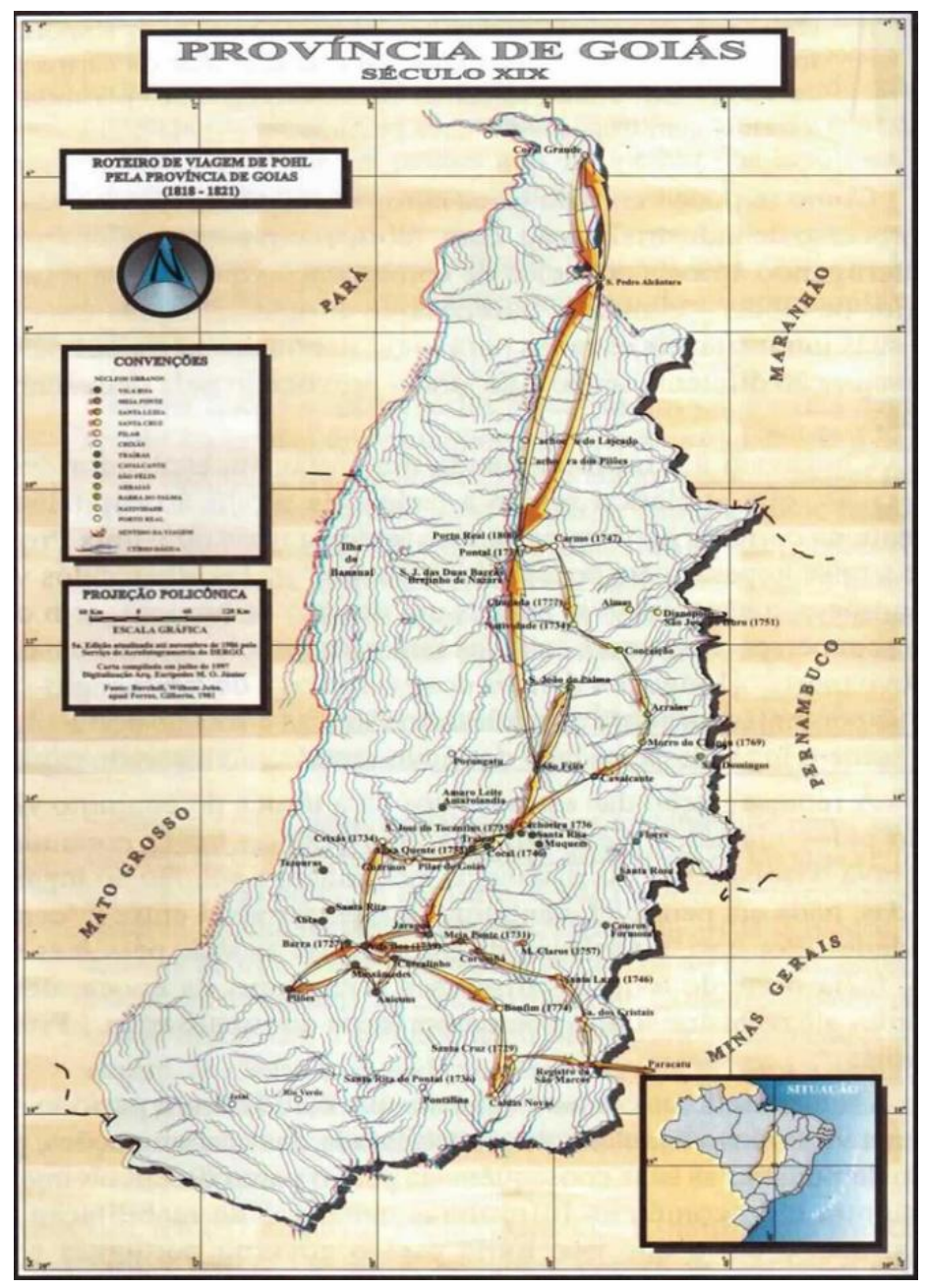

Figura 2: Mapa da viagem de Pohl

Fonte: Doles e Nunes (1992, p. 52)

Quadro 2 - Topônimos identificados por Pohl (1976)

\begin{tabular}{|l|l|}
\hline \multicolumn{1}{|c|}{$\begin{array}{c}\text { TOPÔNIMO } \\
\text { INDÍGENA }\end{array}$} & \multicolumn{1}{c|}{ ETIMOLOGIA SAMPAIO (1987) } \\
\hline Arraial da Anta & - Adj. Forte, duro, rijo. Alt. Ata. \\
\hline $\begin{array}{l}\text { Arraial do Córrego } \\
\text { do Jaraguá }\end{array}$ & $\begin{array}{l}\text { - Corr. Yara-guá, a baixa do senhor, o vale do dono. Pode ser } \\
\text { corrupção de yara-guã, que significa o dedo de Deus, a ponta } \\
\text { do senhor. São Paulo. Goiás, Alagoas. }\end{array}$ \\
\hline $\begin{array}{l}\text { Arraial de São José } \\
\text { do Tocantins }\end{array}$ & $\begin{array}{l}\text { - Corr. Tucan-tim, nariz de tucano. Nome de um gentio que deu } \\
\text { apelido ao rio. Pará. Goiás. } \text { Alt. Tocantim. }\end{array}$ \\
\hline
\end{tabular}




\begin{tabular}{|c|c|}
\hline $\begin{array}{l}\text { Arraial do } \\
\text { Muquém }\end{array}$ & $\begin{array}{l}\text { - Corr. Moca e ou mô-ca-ê, faz que seque, o assador; gradeado } \\
\text { de varas sobre varas para assar a caça ou o peixe. Alt. Muquem. }\end{array}$ \\
\hline Córrego Buriti & $\begin{array}{l}\text { - Corr. Mbiriti, árvore que emite líquido; a palmeira. (Mauritia } \\
\text { Vinifera, Mart). Alt. Murity, Mirity, Mority. }\end{array}$ \\
\hline Córrego $\mathbf{C a}$ & $\begin{array}{l}\text { - Corr. Caapiuar-Y, O Rio Das Capibaras. Bahia, São Paulo, Rio } \\
\text { de Janeiro, Minas Gerais. Alt. Capibary. }\end{array}$ \\
\hline Córre & $\begin{array}{l}\text { - Adj. Forte, duro, valente, sábio; sagrado, santo. Alt. Cary, } \\
\text { caryba, caríua, carahy. }\end{array}$ \\
\hline Córrego Jacuba & $\begin{array}{l}\text { - Corr. Ya-cundá, o indivíduo retorcido ou travado. É um peixe } \\
\text { fluvial vagaroso, que se deixa apanhar à mão. (Bairachops). }\end{array}$ \\
\hline Córrego La1 & $\begin{array}{l}\text { - V. Guanadí. corr. Guá-nhandí, o que é grudento; alusão ao } \\
\text { liquido glutinoso e visguento, de um amarelo fino, que tem a } \\
\text { arevore deste nome. (Calophyllum brasiliense, S. Hill). Alt. } \\
\text { Guanantim, Oanandy, Olandy, Urandy, Landy, Lantim. }\end{array}$ \\
\hline Córrego Tac & - C. Taquar-i, a cana pequena ou fina, o taquaril. \\
\hline Fazenda Jataí & $\begin{array}{l}\text { - V. Guanandí. corr. Guá-nhandí, o que é grudento; alusão ao } \\
\text { líquido glutinoso e visguento, de um amarelo fino, que tem a } \\
\text { árvore deste nome. (Calophyllum brasiliense, S. Hill). Alt. } \\
\text { Guanantim, Oanandy, Olandy, Urandy, Landy, Lantim. }\end{array}$ \\
\hline $\begin{array}{l}\text { Fazenda } \\
\text { Mandaçaia }\end{array}$ & $\begin{array}{l}\text { - C. Manda-çãia, o ninho estendido; alusão à forma do ninho } \\
\text { da abelha deste nome, feito de barro com um orifício de estrada } \\
\text { saliente. (Melípona anthidivides). V. Manda. }\end{array}$ \\
\hline Fazenda do $\mathbf{P}$ & O cercado para apanhar peixe, a \\
\hline Fazenda Sapé & $\begin{array}{l}\text { - Corr. Eçã-pé, ver caminho, aluminar. É a gramínea conhecida } \\
\text { de que se fazem fachos e tetos de habitação. (Saccharum sapê). }\end{array}$ \\
\hline Fazenda Taqu & - C. Taquar-i, a cana pequena ou fina, o taquaril. \\
\hline $\begin{array}{l}\text { Capitania de } \\
\text { Goiás }\end{array}$ & $\begin{array}{l}\text { - Corr. Guayá, c. Guá-yá, o indivíduo semelhante, parecido, ou } \\
\text { gente da mesma raça. Documentos antigos falam em guayás e } \\
\text { guayases, designando uma nação selvagem. Goiás. }\end{array}$ \\
\hline Ilha Cará & $\begin{array}{l}\text { - Corr. Carã, redondo, circular. Pode proceder de acará, o } \\
\text { indivíduo escamoso, cascudo; nome dado a peixe. (Chomis } \\
\text { Acarâ). V. Acará. Designa também uma planta tuberosa } \\
\text { (Dioscorea), como o inhame de São Tomé. }\end{array}$ \\
\hline Morro do Jacaré & $\begin{array}{l}\text { - Corr. Ya-caré, aquele que é torto, ou sinuoso. Pode ser ainda, } \\
\text { y-echá-caré, aquele que olha de banda. (Crocodilus sclerops). }\end{array}$ \\
\hline Ribeirão Suapa & - Corr. Çooaçu-apara, o veado galheiro. V. Suassú. \\
\hline Rio Araguaia & $\begin{array}{l}\text { - S. Ara, o dia, o tempo; a idade, vez; o que está no alto, em cima, } \\
\text { de cima, na eminência; o mundo. Entre os índios do Amazonas, } \\
\text { designa a parte do dia, do meio-dia às cinco horas. O fruto; o } \\
\text { que nasce; o que se colhe; a espiga. }\end{array}$ \\
\hline Rio Buriti & $\begin{array}{l}\text { - Corr. Mbiriti, árvore que emite líquido; a palmeira. (Mauritia } \\
\text { Vinifera, Mart). Alt. Murity, Mirity, Mority. }\end{array}$ \\
\hline
\end{tabular}




\begin{tabular}{|c|c|}
\hline Rio Corumbá & - Corr. Curu-mbá, o banco de cascalho. Mato Grosso. \\
\hline Rio Grajaú & $\begin{array}{l}\text { - Etnol. Obsl. m.q. Caiapó. Etnm. br:: Gradahó. Sing/var. } \\
\text { Gradaú. }\end{array}$ \\
\hline Rio Paraná & $\begin{array}{l}\text { - Corr. Pará-ná, o que é semelhante ao mar; denominação dada } \\
\text { aos grandes rios. Paraná, Parná, Pernam, Fernam. V. } \\
\text { Maranã. }\end{array}$ \\
\hline Rio Piabanha & $\begin{array}{l}\text { - Corr. Piá-bãi, o que é manchado. Batista Caetano. Nome de } \\
\text { um peixe fluvial. Rio de Janeiro. }\end{array}$ \\
\hline Rio Piau & $\begin{array}{l}\text { - Corr. Py-yáu, a pele manchada. É o nome de um peixinho } \\
\text { d'água doce. }\end{array}$ \\
\hline Rio Pirapetinga & $\begin{array}{l}\text { Peixe caraciforme da família dos caracídeos (Bricon opalinus), } \\
\text { encontrados nos rios Paraíbuna e Paraná e também em Goiás. } \\
\text { Etim. Pirape'tinga " peixe da família dos caracídeos" < pi'ra } \\
\text { 'peixe' + pe'tinga 'de casca branca', em que a 'pe 'casca' e 'tinga' } \\
\text { 'branco', ver - tinga; f. hist. } 1869 \text { pyrapitinga, } 1886 \text { pirapitinga. }\end{array}$ \\
\hline Rio Sucuruí & $\begin{array}{l}\text { - Corr. Çuú-curí, morde rápido, atira o bote. E a serpente aquática } \\
\text { Eunects murinus Alt. Socorí. Designa também uma espécie de } \\
\text { caça ou tubarão. }\end{array}$ \\
\hline Rio Surubim & $\begin{array}{l}\text { - Corr. Côo-r-oby, o animal azulado, com laivos azuis. É o peixe } \\
\text { do gênero Platystoma, dos maiores da fauna fluvial, chamado } \\
\text { Jahú, no sul do Brasil. Alt. Sorubi, Suruvi. }\end{array}$ \\
\hline $\begin{array}{l}\text { Rio Taquaruçu } \\
\text { Grande }\end{array}$ & $\begin{array}{l}\text { - Corr. Ta-quara, a haste furada ou oca. Alt. Taquá. Adj. } \\
\text { Grande, considerável. Como substantivo significa o veado. Alt. } \\
\text { Oçú, uçú, guaçú. }\end{array}$ \\
\hline $\begin{array}{l}\text { Rio Taqu } \\
\text { Pequeno }\end{array}$ & $\begin{array}{l}\text { - Corr. Ta-quara, a haste furada ou oca. Alt. Taquá. Adj. } \\
\text { Grande, considerável. Como substantivo significa o veado. Alt. } \\
\text { Oçú, uçú, guaçú. }\end{array}$ \\
\hline Rio Tocan & Nome de um gentio que deu apelido ao rio. Alt. Tocantim. \\
\hline Rio Uruú & $\begin{array}{l}\text { - S. Nome comum das galináceas no tupi. É a ave conhecida } \\
\text { (Odonthophoros dentatus). Designa também um certo tecido de } \\
\text { folhas de palma. }\end{array}$ \\
\hline Serra da & $\begin{array}{l}\text { - C. Voz onomatopaica que se designam os grandes papagaios. } \\
\text { (Psittacus macrocereus). }\end{array}$ \\
\hline Serra do Caiapó & $\begin{array}{l}\text { - Etnol. Grupo indígena que se divide nos subgrupos caiapó- } \\
\text { aucre, caiapó-cararaô, caiapó-cocraimoro, caiapó-cubem- } \\
\text { craquem, caiapó-gorotire, caiapó-mecranoti, caiapó-metuctire, } \\
\text { caiapó-pau-d'arco, caiapó-quicretum e caiapó-xicrim (No } \\
\text { passado eram também chamados de coroados, e os de Mato } \\
\text { Grosso, coroas.) Etim. br: Tupi kaia' pó'o o que traz fogo na } \\
\text { mão, incendiário, queimador. }\end{array}$ \\
\hline Serra do Urubu & $\begin{array}{l}\text { - Corr. Urú-bũ, a galinha preta, a ave negra (Cathartes). Alt. } \\
\text { Urumú. }\end{array}$ \\
\hline
\end{tabular}




\begin{tabular}{|l|l|}
\hline Sítio Bacupari & $\begin{array}{l}\text { Arbusto (S.paniculata) nativo do Brasil (RJ), de folhas ovadas, } \\
\text { flores em panículas e frutos globosos. Etim. Tupi iwakupa'ri } \\
\text { "nome da planta"; segundo Nascentes, de i'watku'ru+pi'ri " } \\
\text { fruto cheio de vilosidades"; f. hist. 1618 ybacropari, 1792 } \\
\text { uvacupary, 1833 bacupari. }\end{array}$ \\
\hline Sítio Caiçara & $\begin{array}{l}\text { - Corr. Caá-içara, a estacada, o tapume, o cercado, a trincheira. } \\
\text { Alt. Caiçá. }\end{array}$ \\
\hline Sítio Cambaúba & $\begin{array}{l}\text { - S.C. Amba-yba, árvore de vazios ou que tem o tronco oco. } \\
\text { Alt. Amba-yba. (Cecropia). }\end{array}$ \\
\hline
\end{tabular}

Fonte: Elaboração própria

\subsection{GEORGE GARDNER}

Gardner foi um famoso botânico escocês que aportou no Brasil, em terras do Rio de Janeiro, em julho de 1836, e permaneceu no país até maio de 1841. Desejando conhecer as variedades dos espécimes naturais dos países dos trópicos, escolheu o Brasil por indicação de seu primeiro patrocinador e então professor de Botânica da Universidade de Glasgow, William T. Hooker. Essa escolha se justificava pelo fato de as produções vegetais desse território ainda serem, em grande parte, desconhecidas pelos ingleses.

Enquanto sua expedição percorria os estados do Rio de Janeiro, Pernambuco, Bahia, Alagoas, Piauí, Maranhão, Goiás e Minas Gerais, Gardner coletou vasto material botânico, retornando à Europa com um herbário de mais de 6.000 espécies. Além disso, estudou o ambiente dessas regiões, fez observações sobre a fauna e a flora, realizou estudos histórico-geográficos e analisou os costumes das populações visitadas. Publicou, de 1842 a 1848, no London Journal of Botany, dirigido por Hooker, suas Contribuitions towards a flora of Brazil. O ilustre botânico interessava-se, sobretudo, pelas províncias do Norte, ainda pouco exploradas por outros naturalistas. Na província de Goiás, de outubro de 1839 a maio de 1840, visitou as regiões compreendidas entre Natividade e Arraias.

Cumpre mencionar que também nos relatos desse naturalista destaca-se uma visão eurocêntrica, por meio da qual valorizava a cultura europeia em detrimento da observada no cotidiano dos habitantes da Província de Goiás. Os costumes dessa população eram avaliados sob a ótica dos seus próprios costumes.

$\mathrm{O}$ viajante descreve os habitantes como homens vadios e indolentes ao extremo e, por isso, sempre há entre eles grande escassez das coisas de necessidade comum da vida. Em sua narrativa, ele revela que,

conquanto grande parte dos arredores da vila muito se preste a plantações de mandioca e outras, bem poucas são as que se veem; e embora haja grandes fazendas de criação de gado a apenas poucas léguas de distância, não se encontra carne fresca à venda senão uma vez por mês; mas isto não admira, pois o grosso da população, por seus hábitos indolentes, não dispõe de recursos para comprar carne ou qualquer outro artigo de utilidade. (GARDNER, 1975, p. 157)

Ignorando as especificidades históricas, sociais e culturais dessa população, o 


\section{Revista \\ A Cor das Letras}

botânico escocês analisava a realidade não objetivamente, mas sim de forma impressionista, utilizando-se para tal de um discurso preconceituoso, em que afiançava constantemente a superioridade do povo europeu.

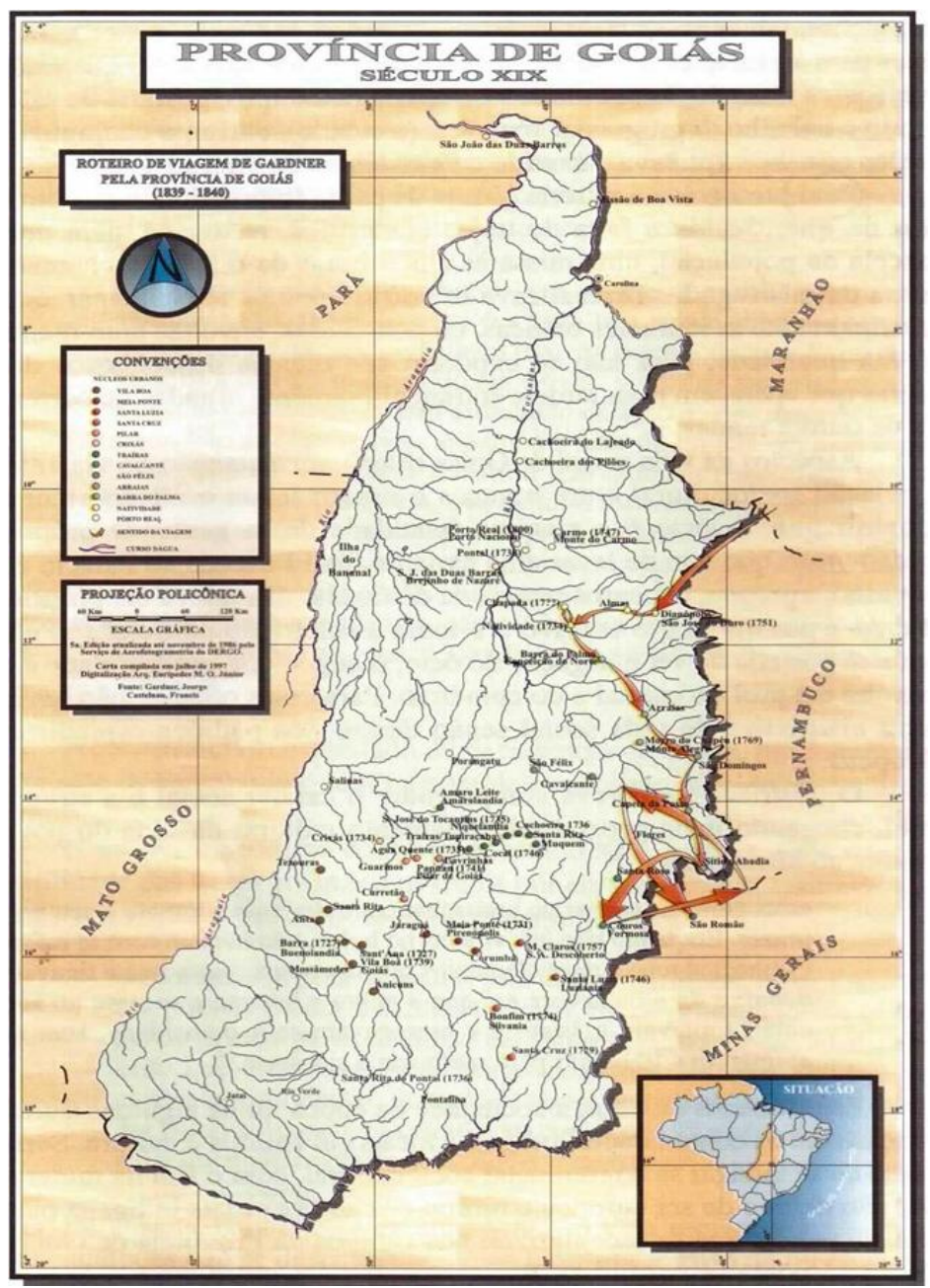

Figura 3: Mapa da viagem de Gardner

Fonte: Doles e Nunes (1992, p. 58)

Quadro 3 - Topônimos identificados por Gardner (1975)

\begin{tabular}{|c|l|}
\hline $\begin{array}{c}\text { Topônimo } \\
\text { Indígena }\end{array}$ & \multicolumn{1}{|c|}{ Etimologia de Sampaio (1987) } \\
\hline $\begin{array}{c}\text { Chapada da } \\
\text { Mangabeira }\end{array}$ & $\begin{array}{l}\text { - Corr. Mongaba, o grude, o visco; alusão ao látex abundante da } \\
\text { planta deste nome. (Hancornia speciosa). Alt. Mongaba, Manguaba. }\end{array}$ \\
\hline Rio Araguaia & $\begin{array}{l}\text { - S. Ara, o dia, o tempo; a idade, vez; o que está no alto, em cima, } \\
\text { de cima, na eminência; o mundo. Entre os índios do Amazonas, }\end{array}$ \\
\hline
\end{tabular}




\begin{tabular}{|c|l|}
\hline & $\begin{array}{l}\text { designa a parte do dia, do meio-dia às cinco horas. O fruto; o que } \\
\text { nasce; o que se colhe; a espiga. }\end{array}$ \\
\hline Rio Tocantins & $\begin{array}{l}\text { - Corr. Tucan-tim, nariz de tucano. Nome de um gentio que deu } \\
\text { apelido ao rio. Pará. Goiás. Alt. Tocantim. }\end{array}$ \\
\hline Serra do Araripe & $\begin{array}{l}\text { - S.C. Ara-ari-pen, literalmente se traduz em sobre o mundo, ou por } \\
\text { sobre o mundo, alusão a ser lugar donde se pode gozar de largo } \\
\text { horizonte. Também Araripe, pode se decompor em ará-ry-pe, e se } \\
\text { traduz no rio dos papagaios. }\end{array}$ \\
\hline
\end{tabular}

\section{Fonte: Elaboração própria}

\subsection{FRANCIS CASTELNAU}

Francis de la Porte, conde de Castelnau, foi o chefe da expedição enviada pelo governo francês ao Brasil. Sua expedição aportou na Província do Rio de Janeiro em 17 de junho de 1843 e permaneceu no país até março de 1847. Durante sua estada nessa província, os membros de sua expedição se ocuparam em realizar excursões botânicas, estudos geológicos, zoológicos e meteorológicos bem como se dedicaram aos preparativos para a extensa viagem que empreenderiam às regiões centrais da América do Sul. Além da Província do Rio de Janeiro, sua expedição percorreu e explorou as de Minas Gerais, Goiás e Mato Grosso. Na Província de Goiás, onde permaneceu de fevereiro a dezembro de 1844, passou pela Vila de Catalão, desceu pelo rio Araguaia e subiu pelo Tocantins, fazendo em sua empreitada um estudo minucioso de descrição da região: população, história e comércio.

A comitiva desse viajante também percorreu as regiões do Paraguai, Bolívia e Peru, de modo que explorou o rio Paraguai, navegando até Assunção, e de Vila Bela viajou para a Bolívia, pelo Potosi, chegando, finalmente, a La Paz, de onde viajou até Lima, local em que permaneceu algum tempo e do qual partiu rumo à Província do Pará, descendo pelo rio Amazonas. Notabiliza-se no discurso desse viajante o estudo acurado ao qual se dedica na descrição da formação geológica e vegetal das regiões que visitou.

O olhar de Castelnau, apesar de mais sutil na percepção da alteridade do que o de outros viajantes naturalistas contemporâneos seus, não deixa de apresentar marcas que revelam a falta de parâmetros na percepção "do outro", como se pode perceber na fala abaixo:

Procurei estudar a acuidade do espírito desse selvagem, o que me foi facilitado pelo seu conhecimento já passável do português. Não tinha ele qualquer espécie de ideia religiosa, parecendo incapaz de conceber o pensamento da Divindade e da imortalidade da alma. Perguntei-lhe o que tinha sido feito dos filhos que foram mortos em combate; respondeume que tinham sido devorados, acabando-se tudo. Alguns eclesiásticos, que em meu quarto assistiam a esses colóquios, puderam, como eu próprio, se assegurar de que na língua daquela gente nem nome existe para exprimir a Divindade. (CASTELNAU, 2000, p. 140)

É possível afirmar que Castelnau, assim como os demais viajantes, era motivado pela cosmovisão europeia na construção de suas narrativas, nas quais se apresentou, em 


\section{Revista \\ A Cor das Letras}

diversos momentos, e por essa razão, acentuadamente etnocêntrico.

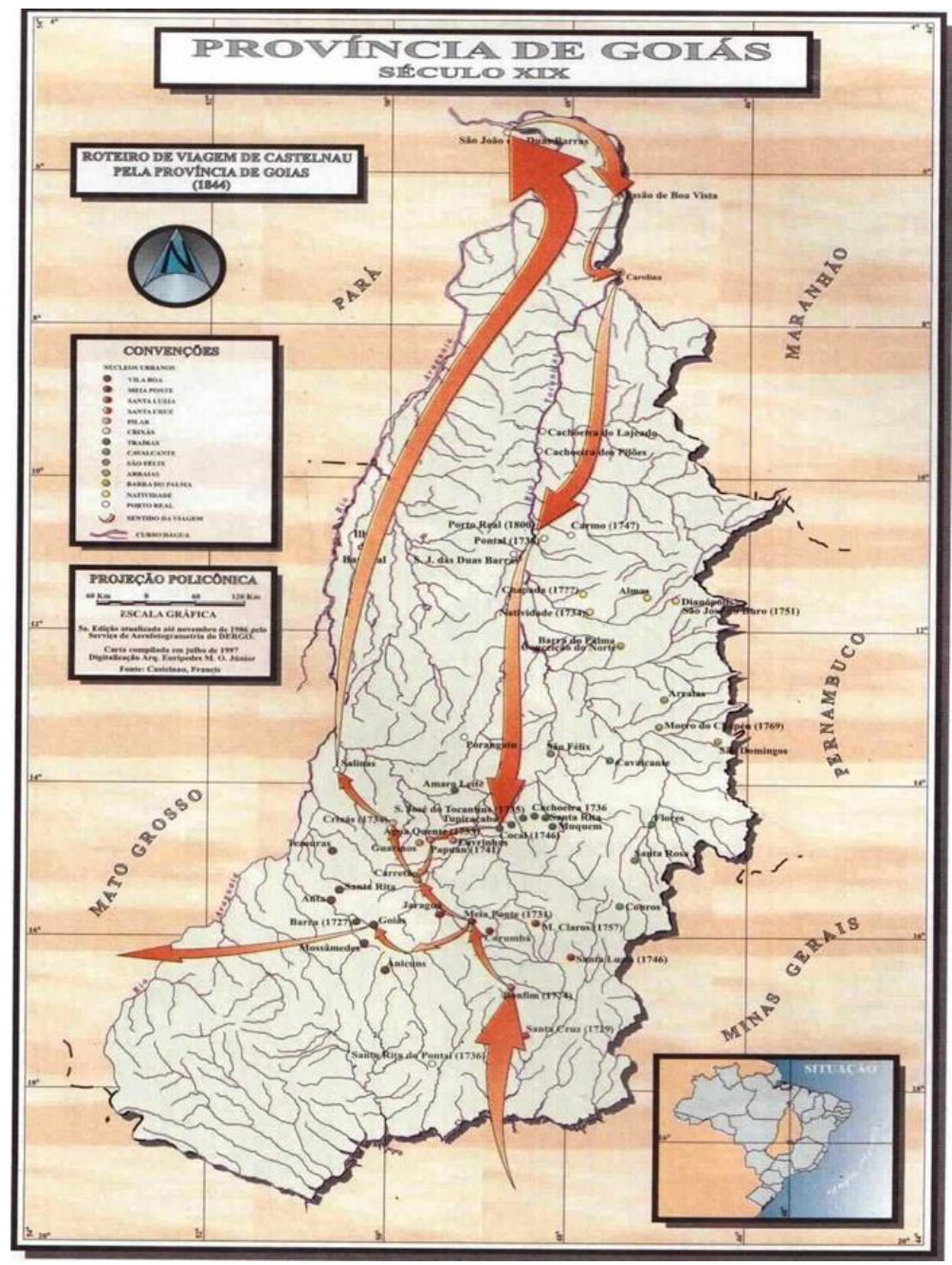

Figura 4: Mapa da viagem de Castelnau

Fonte: Doles e Nunes (1992, p. 65)

Quadro 4 - Topônimos identificados por Castelnau (2000)

\begin{tabular}{|l|l|}
\hline \multicolumn{1}{|c|}{$\begin{array}{c}\text { Topônimo } \\
\text { indígena }\end{array}$} & \multicolumn{1}{c|}{ Etimologia de Sampaio (1987) } \\
\hline Córrego do Buriti & $\begin{array}{l}\text { - Corr. Mbiriti, árvore que emite líquido; a palmeira. (Mauritia } \\
\text { Vinifera, Mart). Alt. Murity, Mirity, Mority. }\end{array}$ \\
\hline Fazenda dos Itãs & $\begin{array}{l}\text { - Corr. Yi-tã, a rã forte; alusão ao coaxar do animal que imita o } \\
\text { som do martelo na bigorna. É a rã de chifre (Ceratophrys } \\
\text { dorsatus, Neuw). Alt. Itanha, Itania. }\end{array}$ \\
\hline
\end{tabular}




\begin{tabular}{|l|l|}
\hline Pouso Tucumã & $\begin{array}{l}\text { - Corr. Tu-cũ, o espinho alongado, apua. É o nome da palmeira } \\
\text { Astrocarium tucumã, cuja haste é guarnecida de longos espinhos, } \\
\text { e de que se tira uma fibra das mais resistentes para linha de } \\
\text { anzóis e para o fabrico de cordas e redes. }\end{array}$ \\
\hline Rio Araguaia & $\begin{array}{l}\text { - S. Ara, o dia, o tempo; a idade, vez; o que está no alto, em } \\
\text { cima, de cima, na eminência; o mundo. Entre os índios do } \\
\text { Amazonas, designa a parte do dia, do meio-dia às cinco horas. } \\
\text { O fruto; o que nasce; o que se colhe; a espiga. }\end{array}$ \\
\hline Rio Capivari & $\begin{array}{l}\text { - Corr. Caapiuar-Y, O Rio Das Capibaras. Bahia, São Paulo, } \\
\text { Rio de Janeiro, Minas Gerais. Alt. Capibary. }\end{array}$ \\
\hline Rio Crixás-açu & $\begin{array}{l}\text { - Adj. Grande, considerável. Como substantivo significa o } \\
\text { veado. Alt. Oçú, uçú, guaçú. }\end{array}$ \\
\hline Rio Crixás-Mirim & $\begin{array}{l}\text { - Adj. Pequeno, breve, pouco, miúdo; adj. Um pouco. Alt. Mir, } \\
\text { mĩ, minĩ, ĩ. }\end{array}$ \\
\hline Rio Maranhão & $\begin{array}{l}\text { - Corr. Mbará-nhã, o mar corrente; o grande caudal que simula } \\
\text { o mar a correr. Alt. Manarã, Paraná. V. Mbará. }\end{array}$ \\
\hline Rio Tocantins & $\begin{array}{l}\text { - Corr. Tucan-tim, nariz de tucano. Nome de um gentio que } \\
\text { deu apelido ao rio. Pará. Goiás. Alt. Tocantim. }\end{array}$ \\
\hline Rio Taquaruçu & $\begin{array}{l}\text { - Corr. Ta-quara, a haste furada ou oca. Alt. Taquá. Adj. } \\
\text { Grande, considerável. Como substantivo significa o veado. } \\
\text { Alt. Oçú, uçú, guaçú. }\end{array}$ \\
\hline Rio Uruu & $\begin{array}{l}\text { - S. Nome comum das galináceas no tupi. É a ave conhecida } \\
\text { (Odonthophoros dentatus). Designa também um certo tecido de } \\
\text { folhas de palma. }\end{array}$ \\
\hline Tocantins & $\begin{array}{l}\text { - Corr. Tucan-tin, nariz de tucano. Nome de um gentio que } \\
\text { deu apelido ao rio. Alt. Tocantim. }\end{array}$ \\
\hline
\end{tabular}

Fonte: Elaboração própria

\section{CONSIDERAÇÕES FINAIS}

Os relatos dos viajantes estrangeiros são alguns dos elementos fundamentais na construção da identidade brasileira. No que tange à Província de Goiás, essas narrações permitem reconstituir parte da história regional. A despeito do fato de o discurso utilizado nessas fontes ser marcadamente preconceituoso, as observações feitas possibilitam regatar, mesmo que mediadas por suas impressões, informações sobre o caráter sociocultural e geográfico da região bem como sobre o seu perfil etnolinguístico.

Esses viajantes tinham como principal interesse em suas viagens ao território brasileiro realizar estudos e pesquisas de caráter botânico, geomorfológico, zoológico e antropológico. Saint-Hilaire, Pohl, Gardner e Castelnau foram alguns dos iminentes naturalistas que realizaram excursões pela Província de Goiás ao longo século XIX. O interesse de empreender viagens de cunho científico nessa província se devia ao fato de ela ainda ser naquele século um território pouco explorado e que oferecia inúmeras possibilidades de pesquisa. Além disso, esses viajantes naturalistas desejavam conhecer as 
técnicas utilizadas na extração de ouro, não obstante a produção aurífera estivesse decadente e deixado de ser a base da economia dessa região, bem como do país, no início do século XIX.

Chegavam à Província de Goiás imaginando-a em esplendor devido à atividade mineratória, todavia a encontraram em uma situação de decadência. Para os viajantes, que não compreendiam as razões que levaram a província àquela situação, o estado em que a mesma se encontrava era lastimável e opunha-se radicalmente ao imaginário de fausto que haviam vislumbrado sobre a região em razão da mineração, que a incluiria no ideal de progresso representado pelo capitalismo.

Imbuídos dessa concepção capitalista, referiram-se ao cotidiano da população da Província de Goiás como sendo caracterizado pela ociosidade. Os costumes observados se contrapunham frontalmente ao que determinava essa concepção, uma vez que as atividades produtivas dessa população não se regulavam pelo "tempo-relógio" capitalista, cujo objetivo principal era fomentar o desenvolvimento do trabalho constante e sistemático, mas, sim, pelas suas necessidades primárias, essencialmente ligadas à caça, pesca e coleta de frutos silvestres e mel, ou seja, sazonal e dependente do ciclo da natureza. Em vista do contexto dessa província, os viajantes naturalistas interpretaram a realidade que observaram a partir de seus próprios valores e visões de mundo, de forma impressionista, fato esse que culminou em discursos etnocêntricos.

\section{REFERÊNCIAS}

ANDRADE, Karylleila dos Santos. Atlas toponímico de origem indígena do Estado do Tocantins: Atito. Goiânia: Ed. da PUC de Goiás, 2010.

BASTIANI, C. Topônimos, nomes de escola e memória: o léxico como repertório do conhecimento cultural. DLCV, v. 12, n. 2, João Pessoa, jul./dez. 2016.

CASTELNAU, Francis. Expedição às regiões centrais da América do Sul. Belo Horizonte; Rio de Janeiro: Itatiaia, 2000.

CHAUL, Nasr Nagib Fayad. Caminhos de Goiás: da construção da decadência aos limites da modernidade. Goiânia: Ed. da UFG, 2002.

DICK, Maria Vicentina de Paula do Amaral. A motivação toponímica e a realidade brasileira. São Paulo: Arquivo do Estado de São Paulo, 1990.

DOLES, D. E. M.; NUNES, H. P. Memória da ocupação de Goiás na primeira metade do século XIX: a visão dos viajantes europeus. Ciências Humanas em Revista - História, v. 3, n. 1-2, Goiânia, jan./dez. 1992.

GARDNER, George. Viagem ao interior do Brasil, principalmente nas provincias do Norte e nos distritos do ouro e do diamante durante os anos de 1836-1841. Tradução de Milton Amado. Belo Horizonte/São Paulo: Itatiaia/EDUSP, 1975.

POHL, Joahann Emmanuel. Viagem no interior do Brasil. Tradução de Milton Amado e Eugênio Amado. São Paulo: EDUSP, 1976.

SAINT-HILAIRE, August de. Viagem à provincia de Goiás. Tradução de Regina Regis Junqueira. Belo Horizonte/São Paulo: Itatiaia/EDUSP, 1975. 
